\title{
Optimization of TBAB-Assisted Lipase-catalyzed Synthesis of L-Ascorbyl Myristate
}

\author{
H. Li, ${ }^{\text {a,b, }}$ L. Zhang, ${ }^{a, b}$ R. Shen, ${ }^{a, b}$ and Y. Liu ${ }^{a, b}$ \\ ${ }^{a}$ School of Food and Biological Engineering, Zhengzhou University \\ of Light Industry, Zhengzhou, Henan Province, China \\ ${ }^{b}$ Henan Collaborative Innovation Center for Food Production \\ and Safety, Zhengzhou, Henan Province, China
}

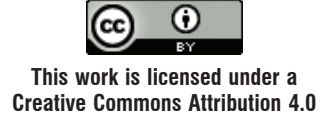

Creative Commons Attribution 4.0 International License

doi: 10.15255/CABEQ.2016.978

Original scientific paper

Received: September 10, 2016

Accepted: May 8, 2018

The synthesis of L-ascorbyl myristate through esterification of L-ascorbic acid and myristic acid catalyzed by lipase was studied. The effect of different parameters including lipase, molecular sieve $4 \AA$, organic solvent, and tetrabutyl ammonium bromide (TBAB) was evaluated. The results showed excellent yield in the presence of Novozyme 435 as catalyst, $10 \%$ (w/w of L-ascorbic acid) of $4 \AA$ molecular sieve and $10 \%$ (w/w of L-ascorbic acid) of TBAB as additives in 1,4-dioxane. Furthermore, response surface methodology (RSM) and 5-level-4-factor central composite design (CCD) were employed to evaluate the effects of parameters on the yield of L-ascorbyl myristate. According to the analysis result of ridge max, the optimal synthesis conditions were predicted, as follows: reaction time $27.1 \mathrm{~h}$, temperature $54.1^{\circ} \mathrm{C}$, enzyme amount $25.9 \%(\% \mathrm{w} / \mathrm{w}$ of L-ascorbic acid), substrate molar ratio 5 , and the optimal actual yield was $85.0 \%$.

Key words:

L-ascorbyl myristate, Novozyme435, TBAB, Response Surface Methodology

\section{Introduction}

Antioxidants are widely used in foods and cosmetics to prevent oxidation of lipids ${ }^{1-3}$. Among the available antioxidants, synthetic antioxidants, such as butylated hydroxyanisole (BHA) and butylated hydroxytoluene (BHT), are the most widely used as food additives, but their application has been reassessed because of possible toxicity or carcinogenic components formed during degradation ${ }^{2-4}$.

L-Ascorbic acid (Vitamin C) is a widely used natural hydrophilic antioxidant ${ }^{2,5}$. However, its high hydrophilicity limits its application in hydrophobic foods and cosmetics ${ }^{6,7}$. Modification of L-ascorbic acid via esterification or transesterification with aliphatic molecule, such as fatty acids or esters, is a useful way to impart hydrophobic property, which not only improves its oil-solubility but also enhances its radical scavenging potential as compared to its free counterpart ${ }^{2,8}$ in inhibition of enzymic browning in apple juice ${ }^{9}$ and preventing sunburn damage to the $\operatorname{skin}^{10,11}$. The most interesting derivatives, esters of fatty acids (palmitic, oleic, etc.) and ascorbic acid, are already accepted as food additives $^{12}$. Unsaturated fatty acids have more beneficial effects on human nutrition than saturated fatty acids ${ }^{13}$. In particular, conjugated linoleic acid (CLA) has attracted considerable attraction due to its mul-

"Corresponding author: Hong Li; Tel.: +8613523435960;

e-mail address: hnzzlihong@163.com tiple physiological characteristrics, such as antioxidant property ${ }^{14}$. Furthermore, conjugated linoleoyl ascorbate has higher oxidative stability than unmodified CLA ${ }^{15}$.

L-Ascorbyl esters are produced commercially by chemical methods ${ }^{16}$. This chemical process has some disadvantages, such asthe use of strong acids, low yields due to non-regioselective reactions, formation of by-products due to instability of vitamin $\mathrm{C}$, and the need of tedious product isolation. As an alternative, lipase-catalyzed synthesis of L-ascorbyl esters has received considerable attention due to mild reaction conditions and high regioselectivity. Humeau et al. reported the lipase-mediated synthesis of L-ascorbyl esters through transesterification by using immobilized lipase (Novozyme435) and lipase $\mathrm{B}(C \text {. antarctica })^{17,18}$. The maximum yield was only $40 \%$. To improve the yield of the product, Yan et al. ${ }^{19}$ and Zhang ${ }^{20}$ investigated the enzymatic synthesis of vitamin $\mathrm{C}$ fatty acid esters using fatty acid vinyl esters as acyl donor, and obtained the corresponding products in $91 \%$ isolated yield and a maximum conversion of $99 \%$. To shorten the reaction time, ultrasound $\mathrm{d}^{21}$ and microwave technology ${ }^{22,23}$ have been used in the enzymatic synthesis of L-ascorbyl fatty acid esters, resulting in an ascorbyl fatty acid ester yield of $70 \%$. However, the advances are limited by the low solubility of ascorbic acid in conventional solvents. Park et al. ${ }^{24}$, Adamczak ${ }^{25}$ and $\mathrm{Xu}^{26}$ reported the enzymatic synthesis of L-ascorbyl oleate and CLA ascorbyl ester by ionic 
liquid-based reaction system, which resulted in 61 $\%, 72 \%$ yield and $120-200 \mathrm{~g} \mathrm{~L}^{-1}$ productivity, respectively. However, the synthesis of the ionic liquids is complex. Shieh ${ }^{27}$ optimized the synthesis of lipase-catalyzed L-ascorbyl laurate by Novozyme435 using response surface methodology, and obtained the optimal actual yield of $91 \%$. In this work, tetrabutyl ammonium bromide (TBAB) was used as ionic surfactant in the reaction system to investigate whether its addition would improve the solubility of ascorbic acid in solvents, which can increase the volumetric productivity of the L-ascorbyl esters catalyzed by NOVO435. Moreover, the purpose of the present study was to optimize the biosynthesis process using a statistical approach and to better understand the relationship between various reaction variables.

\section{Materials and methods}

\section{Materials}

Novozyme435 (from Candida antarctica), LIPOLASE and Lipozyme TLIM were purchased from Novozymes A/S Bioindustrial, Inc. (Bagsvaerd, Denmark). L-Ascorbic acid (99\%), myristic acid $(98 \%)$, tetrabutyl ammonium bromide (TBAB) and molecular sieves $4 \AA$ were purchased from Sinopharm Chemical Reagent Co. Ltd. (Shanghai, China). All other chemicals used were of analytical reagent grade. All the solvents were stored over activated molecular sieves $4 \AA$ prior to use.

\section{Methods}

General procedure for enzymatic synthesis of L-ascorbyl myristate

Molecular sieve $4 \AA(10 \%$ w/w of L-ascorbic acid) was added to all liquid materials to remove trace water for $24 \mathrm{~h}$ before use. L-Ascorbic acid $(0.5 \mathrm{mmol})$ and different molar ratios of myristic acid (1-5) were added into $5 \mathrm{~mL}$ solvent (tert-amyl alcohol, acetonitrile, acetone, hexane, 1,4-dioxane and methanol) in $25-\mathrm{mL}$ conical flask with cover, followed by different amounts of enzyme (10-50\% $\mathrm{w} / \mathrm{w}$ of L-ascorbic acid). The mixtures containing L-ascorbic acid, myristic acid, enzyme, molecular sieve $4 \AA$ (10\% w/w of L-ascorbic acid), TBAB (10 $\% \mathrm{w} / \mathrm{w}$ of L-ascorbic acid) and solvent were stirred in an orbital shaking water bath $(180 \mathrm{rpm})$ at different reaction temperatures $\left(40-60{ }^{\circ} \mathrm{C}\right)$ for certain reaction times $(12-36 \mathrm{~h})$.

\section{Yield of the L-ascorbyl myristate}

After defined time, the reaction mixture was filtered to remove enzyme and molecular sieve $4 \AA$, followed by rotary evaporation in vacuum. Ten milliliters of ethyl acetate was added to the residue and extracted with water three times to remove unreacted L-ascorbic acid. The organic phase was condensed under reduced pressure followed by adding $10 \mathrm{~mL}$ ethyl alcohol and $6 \mathrm{~mL}$ water. The mixed solution was titrated with $0.1 \mathrm{~mol} \mathrm{~L}^{-1}$ iodine standard solution until the mixed solution turned yellow giving the amount of L-ascorbyl myristate ${ }^{28}$. Yield (\%) of the L-ascorbyl myristate was calculated by dividing the initial molar amount of L-ascorbic acid by the produced molar amount of L-ascorbyl myristate.

\section{Experimental design}

In order to optimize the reaction conditions, a 5-level-4-factor central composite design (CCD) from Design-Expert 8.0.5 was employed in this study, requiring 27 experiment points (16 factorial points, 8 axial points, and 3 center points) to explore the interactions between reaction time, temperature, enzyme amount, and substrate molar ratio $^{29}$. The yield of L-ascorbyl myristate was studied as a response, the value $(Y)$ of which in each trial was the average of duplicates. All 27 runs were performed in a totally random order so that systematic errors would be avoided.

\section{Statistical analysis}

The experimental data were analyzed by the response surface regression (Proc RSREG) procedure to fit the following second-order polynomial equa$\operatorname{tion}^{30}$.

$$
Y=\beta_{k 0}+\sum_{i=1}^{4} \beta_{k i} x_{i}+\sum_{i=1}^{4} \beta_{k i i} x_{i}^{2}+\sum_{i=1}^{3} \sum_{j=i+1}^{4} \beta_{k i j} x_{i} x_{j}
$$

Where $Y$ is response (yield); $b_{k 0}, b_{k i}, b_{k i i}$ and $b_{k i j}$ are constant coefficients, and $x_{i}$ is the uncoded independent variable. The option of RIDGE MAX was employed to compute the estimated ridge of maximum response for increasing radii from the center of the original design.

\section{Purification of L-ascorbyl myristate}

Enzymatic esterification was performed using the following protocol: $0.88 \mathrm{~g}$ L-Ascorbic acid as reacted with $5.7 \mathrm{~g}$ of myristic acid, $0.228 \mathrm{~g}$ of Novozyme $435,0.088 \mathrm{~g}$ molecular sieve $4 \AA, 0.088 \mathrm{~g}$ TBAB in 1,4-dioxane at $54.1{ }^{\circ} \mathrm{C}$ for $27.1 \mathrm{~h}$. Upon the completion of the reaction, the enzyme and molecular sieve $4 \AA$ were filtered off, and the filtrate was concentrated using arotary evaporator. Twenty milliliters of ethyl acetate was added to the residue and then extracted with water three times to remove unreacted L-ascorbic acid. The organic phase was 
condensed under reduced pressure and then solved in $20 \mathrm{~mL}$ toluene at $60{ }^{\circ} \mathrm{C}$. The liquid was placed at ambient temperature for $24 \mathrm{~h}$ before white crystals appeared. After the white crystals were washed with petroleum ether, $1.5 \mathrm{~g}$ of white thin piece of crystal with a yield of $77.7 \%$ was obtained by recrystallization.

\section{Structure confirmation of L-ascorbyl myristate}

The structure of L-ascorbyl myristate was identified by ESI-MS and ${ }^{1} \mathrm{H}$ NMR.

Mass spectrometer analysis in the negative ion mode was performed on Thermo Fisher LTQXL, over a mass range of $\mathrm{m} / \mathrm{z} 300 \sim 500$. The electrospray ionization mass spectrometry (ESI-MS) source operating conditions were as follows: capillary voltage of $5.0 \mathrm{~V}$, scan time of $0.5 \mathrm{~s}$, and capillary temperature of $350{ }^{\circ} \mathrm{C}$. The purified product was dissolved in methanol to a final concentration of 10 $\mathrm{mg} \mathrm{L}^{-1}$. The solution was injected into the electrospray ion-source at a $10 \mu \mathrm{L} \mathrm{min}{ }^{-1}$ flow rate.

1 HNMR spectra of L-ascorbyl myristate in DMSO was recorded on a Bruker Avance spectrometer 600 (BrukerBiospin Co., Billerica, MA, USA) at $600 \mathrm{MHz}$ using tetramethylsilane (TMS) as internal standard.

\section{Results and discussion}

\section{Preliminary tests}

Initially, the enzymatic syntheses of L-ascorbyl myristate were carried out with various enzyme, solvent, and additives. The results are shown in Table 1. The catalytic activity of Novozyme435, TLIM and LIPOLASE was first tested (entries 1-3), and Novo435 exhibited the highest activity with a loading of $30 \% \mathrm{w} / \mathrm{w}$ of L-ascorbic acid. Higher yield was obtained after the addition of molecular sieve $4 \AA$ (10\% w/w of L-ascorbic acid) (entries 1, 4). After screening a variety of solvents, 1,4-dioxane was superior to others (entries 4-8). Finally, TBAB $(10 \% \mathrm{w} / \mathrm{w}$ of L-ascorbic acid) was added to the reaction system to investigate the effect of ionic surfactant, and excellent yield was obtained (entry 9), which is probably because of the addition of TBAB increasing the solubility of ascorbic acid in 1,4-dioxane.

\section{Statistical experimental designs}

Model fitting

After determining the preliminary experimental condition that afforded the highest yield, a

Table 1 -Effect of enzymes, solvents, additives on the enzymatic synthesis of L-ascorbyl myristate<smiles>O=C1OC(C(O)CO)C(O)=C1O</smiles>

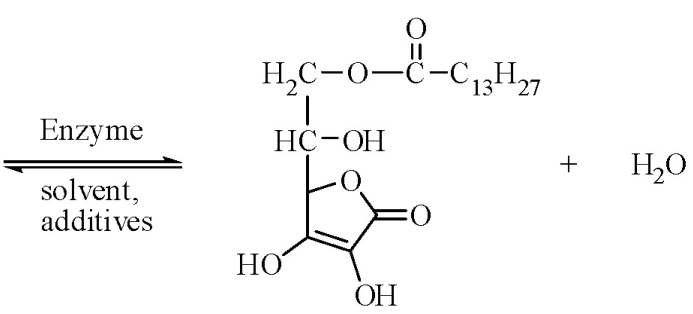

L-ascorbic acid

myristic acid

L-ascorbyl myristate

water

\begin{tabular}{c|c|c|c|c}
\hline Entry & Enzyme & Solvent & Additive & Yield (\%) \\
\hline 1 & Novozyme435 & tert-amyl alcohol & - & 54.8 \\
2 & TLIM & tert-amyl alcohol & - & 6.79 \\
3 & LIPOLASE & tert-amyl alcohol & molecular sieve $4 \AA$ & 0.56 \\
4 & Novozyme435 & tert-amyl alcohol & molecular sieve 4 $\AA$ & 67.1 \\
5 & Novozyme435 & acetonitrile & molecular sieve $4 \AA$ & 61.9 \\
6 & Novozyme435 & acetone & molecular sieve $4 \AA$ & 66.5 \\
7 & Novozyme435 & hexane & molecular sieve $4 \AA$ & 63.5 \\
8 & Novozyme435 & 1,4-dioxane & molecular sieve 4 $\AA+$ TBAB & 70.6 \\
9 & Novozyme435 & 1,4-dioxane & 79.8 \\
\hline
\end{tabular}

Reaction conditions: L-ascorbic acid $(0.5 \mathrm{mmol})$, myristic acid $(1.5 \mathrm{mmol})$, enzyme $(30 \% \mathrm{w} / \mathrm{w}$ of L-ascorbic acid $)$, solvent $(5 \mathrm{~mL})$, temperature $\left(50{ }^{\circ} \mathrm{C}\right)$, time $(24 \mathrm{~h})$, rotation rate $(180 \mathrm{rpm})$. 
5-level-4-factor CCD including 27 experimental points was employed to further maximize the yield of L-ascorbyl myristate. The variables and their levels selected based on the preliminary studies on the synthesis of L-ascorbyl myristate are presented in
Table 2. Table 3 shows the matrix with code values, real values, and the yields obtained. The highest yield $(84.5 \%)$ was obtained under the following experimental conditions: reaction time $24 \mathrm{~h}$, temperature $50{ }^{\circ} \mathrm{C}, 30 \%$ of enzyme, substrate molar ratio 5

Table 2 - Variable levels for central composite rotatory design experiment

\begin{tabular}{l|c|c|c|cc}
\hline \multicolumn{1}{c}{ Variable } & \multicolumn{4}{c}{ Level } \\
\cline { 2 - 6 } & -2 & -1 & 0 & 1 & 2 \\
\hline Reaction time $(\mathrm{h})$ & 12 & 18 & 24 & 30 & 36 \\
Temperature $\left({ }^{\circ} \mathrm{C}\right)$ & 40 & 45 & 50 & 55 & 60 \\
Enzyme amount $(\%$ w/w of L-ascorbic acid) & 10 & 20 & 30 & 40 & 50 \\
Substrate molar ratio (myristic acid/L-ascorbic acid) & 1 & 2 & 3 & 4 & 5 \\
\hline
\end{tabular}

Table 3 -Experimental matrix with code and real values and experimental data for 5-level-4-factor response surface analysis

\begin{tabular}{|c|c|c|c|c|c|}
\hline Entry & $\begin{array}{c}\text { Time (h) } \\
x_{1}\end{array}$ & $\begin{array}{c}\text { Temperature }\left({ }^{\circ} \mathrm{C}\right) \\
x_{2} \\
\end{array}$ & $\begin{array}{c}\text { Enzyme amount } \\
(\% \mathrm{w} / \mathrm{w} \text { of } \mathrm{L}-\text { ascorbic acid }) \\
x_{3}\end{array}$ & $\begin{array}{c}\text { Substrate molar ratio } \\
\text { (myristic acid/L-ascorbic acid) } \\
x_{4}\end{array}$ & $\begin{array}{l}\text { Yield }^{\mathrm{a}} \\
(\%) \\
Y\end{array}$ \\
\hline 1 & $30(+1)$ & $55(+1)$ & $40 \%(+1)$ & $4(+1)$ & 81.6 \\
\hline 2 & $18(-1)$ & $45(-1)$ & $40 \%(+1)$ & $4(+1)$ & 73.2 \\
\hline 3 & $24(0)$ & $40(-2)$ & $30 \%(0)$ & $3(0)$ & 69.9 \\
\hline 4 & $24(0)$ & $50(0)$ & $50 \%(+2)$ & $3(0)$ & 74.3 \\
\hline 5 & $24(0)$ & $50(0)$ & $30 \%(0)$ & $3(0)$ & 79.6 \\
\hline 6 & $30(+1)$ & $45(-1)$ & $20 \%(-1)$ & $2(-1)$ & 64.8 \\
\hline 7 & $18(-1)$ & $45(-1)$ & $20 \%(-1)$ & $2(-1)$ & 62.4 \\
\hline 8 & $18(-1)$ & $55(+1)$ & $20 \%(-1)$ & $4(+1)$ & 79.7 \\
\hline 9 & $30(+1)$ & $45(-1)$ & $40 \%(+1)$ & $4(+1)$ & 75.4 \\
\hline 10 & $30(+1)$ & $45(-1)$ & $40 \%(+1)$ & $2(-1)$ & 68.2 \\
\hline 11 & $12(-2)$ & $50(0)$ & $30 \%(0)$ & $3(0)$ & 71.7 \\
\hline 12 & $24(0)$ & $50(0)$ & $30 \%(0)$ & $3(0)$ & 79.9 \\
\hline 13 & $24(0)$ & $60(+2)$ & $30 \%(0)$ & $3(0)$ & 75.5 \\
\hline 14 & $30(+1)$ & $45(-1)$ & $20 \%(-1)$ & $4(+1)$ & 75.7 \\
\hline 15 & $30(+1)$ & $55(+1)$ & $20 \%(-1)$ & $4(+1)$ & 79.9 \\
\hline 16 & $18(-1)$ & $55(+1)$ & $40 \%(+1)$ & $4(+1)$ & 79.5 \\
\hline 17 & $18(-1)$ & $55(+1)$ & $40 \%(+1)$ & $2(-1)$ & 72.2 \\
\hline 18 & $24(0)$ & $50(0)$ & $10 \%(-2)$ & $3(0)$ & 68.5 \\
\hline 19 & $36(+2)$ & $50(0)$ & $30 \%(0)$ & $3(0)$ & 74.9 \\
\hline 20 & $18(-1)$ & $55(+1)$ & $20 \%(-1)$ & $2(-1)$ & 71.2 \\
\hline 21 & $24(0)$ & $50(0)$ & $30 \%(0)$ & $5(+2)$ & 84.5 \\
\hline 22 & $18(-1)$ & $45(-1)$ & $20 \%(-1)$ & $4(+1)$ & 75.1 \\
\hline 23 & $30(+1)$ & $55(+1)$ & $20 \%(-1)$ & $2(-1)$ & 72.4 \\
\hline 24 & $30(+1)$ & $55(+1)$ & $40 \%(+1)$ & $2(-1)$ & 72.7 \\
\hline 25 & $24(0)$ & $50(0)$ & $30 \%(0)$ & $3(0)$ & 80.1 \\
\hline 26 & $18(-1)$ & $45(-1)$ & $40 \%(+1)$ & $2(-1)$ & 73.9 \\
\hline 27 & $24(0)$ & $50(0)$ & $30 \%(0)$ & $1(-2)$ & 65.4 \\
\hline
\end{tabular}

a Reaction conditions: L-ascorbic acid $(0.5 \mathrm{mmol})$, molecular sieve $4 \AA$ (10 \% w/w L-ascorbic acid), TBAB (10 \% w/w of L-ascorbic acid), 1,4-dioxane $(5 \mathrm{~mL})$, rotation rate $(180 \mathrm{rpm})$. 
(entry 21, Table 3). From the SAS output of RSREG, the second-order polynomial Eq. (1) was given as follows:

$$
\begin{aligned}
Y & =79.87+0.41 x_{1}+2.15 x_{2}+1.13 x_{3}+4.19 x_{4}+ \\
& +0.28 x_{1} x_{2}-0.33 x_{1} x_{3}+0.42 x_{1} x_{4}- \\
& -0.62 x_{2} x_{3}+0.13 x_{2} x_{4}-1.06 x_{2} x_{4}- \\
& -1.55 x_{1}^{2}-1.70 x_{2}^{2}-2.03 x_{3}^{2}-1.14 x_{4}^{2}
\end{aligned}
$$

The analysis of variance (ANOVA) for response surface quadratic model shown in Table 4 indicated that the second-order polynomial model (Eq. (2)) was statistically significant and adequate to represent the relationship between the response (yield) and the significant variables, with the model of $F$-value of 11.75 and very small $p$ value $(p<$ 0.0001 ). Values of $p$ less than 0.0500 indicate the model terms are significant. In general, the higher $F$-value means the greater significance of the corresponding coefficient ${ }^{31}$. Table 4 revealed that the reaction temperature $\left(x_{2}\right)$, enzyme amount $\left(x_{3}\right)$, and substrate molar ratio $\left(x_{4}\right)$ were the most important factors that exhibited a statistically significant overall effect $(p<0.05)$ on the yield of L-ascorbyl myristate. However, reaction time $\left(x_{1}\right)$ showed a less significant effect $(p>0.05)$ on the enzymatic synthesis of L-ascorbyl myristate. The value of determination coefficient $\left(R^{2}\right)$ was 0.9320 , which implied that 93.2 $\%$ of the variation in the production yield could be explained by the regression model.

\section{Mutual effect of parameters}

The optimum level of each variable and the effect of their interactions on the yield of L-ascorbyl myristate were studied by plotting 3D response surfaces against any two independent variables, while the other variables were fixed at zero level. The results are given in Figs. 1a-f. Fig. 1a shows the effect of reaction time, temperature, and their mutual interaction on L-ascorbyl myristate synthesis at 30 $\%$ of enzyme amount and 3 of substrate molar ratio. As the reaction time progressed and temperature increased, the yield increased, and then decreased when time was over $24 \mathrm{~h}$ and temperature was above $50{ }^{\circ} \mathrm{C}$, which maybe because of the slight reverse reaction of esterification and decreased activity of lipase. Moreover, the effect of reaction time was lower than the effect of temperature. This result was consistent with that obtained from Table 4, which indicated that reaction time $\left(x_{1}\right)$ had no sig-

\begin{tabular}{|c|c|c|c|c|c|}
\hline Source & Sum of squares & $\mathrm{df}$ & Mean square & $F$-value & $p$-value \\
\hline Model & 720.08 & 14 & 51.43 & 11.75 & $<0.0001$ \\
\hline$x_{1}$ & 4.08 & 1 & 4.08 & 0.93 & 0.3532 \\
\hline$x_{2}$ & 111.37 & 1 & 111.37 & 25.43 & 0.0003 \\
\hline$x_{3}$ & 30.60 & 1 & 30.60 & 6.99 & 0.0214 \\
\hline$x_{4}$ & 420.84 & 1 & 420.84 & 96.11 & $<0.0001$ \\
\hline$x_{1} x_{2}$ & 1.27 & 1 & 1.27 & 0.29 & 0.6007 \\
\hline$x_{1} x_{3}$ & 1.76 & 1 & 1.76 & 0.40 & 0.5385 \\
\hline$x_{1} x_{4}$ & 2.81 & 1 & 2.81 & 0.64 & 0.4390 \\
\hline$x_{2} x_{3}$ & 6.13 & 1 & 6.13 & 1.40 & 0.2598 \\
\hline$x_{2} x_{4}$ & 0.28 & 1 & 0.28 & 0.063 & 0.8061 \\
\hline$x_{3} x_{4}$ & 17.85 & 1 & 17.85 & 4.08 & 0.0664 \\
\hline$x_{1}^{2}$ & 51.46 & 1 & 51.46 & 11.75 & 0.0050 \\
\hline$x_{2}^{2}$ & 61.88 & 1 & 61.88 & 14.13 & 0.0027 \\
\hline$x_{3}^{2}$ & 87.75 & 1 & 87.75 & 20.04 & 0.0008 \\
\hline$x_{4}^{2}$ & 27.76 & 1 & 27.76 & 6.34 & 0.0270 \\
\hline Residual & 52.54 & 12 & 4.38 & & \\
\hline Lack of fit & 52.42 & 10 & 5.24 & 82.76 & 0.0120 \\
\hline Pure error & 0.13 & 2 & 0.063 & & \\
\hline Cor Total & 772.63 & 26 & & & \\
\hline$R$-Squared & 0.9320 & & & & \\
\hline
\end{tabular}
nificant effect $(p>0.05)$ on the biosynthesis of L-ascorbyl myristate.

Table 4-ANOVA for response surface quadratic model 

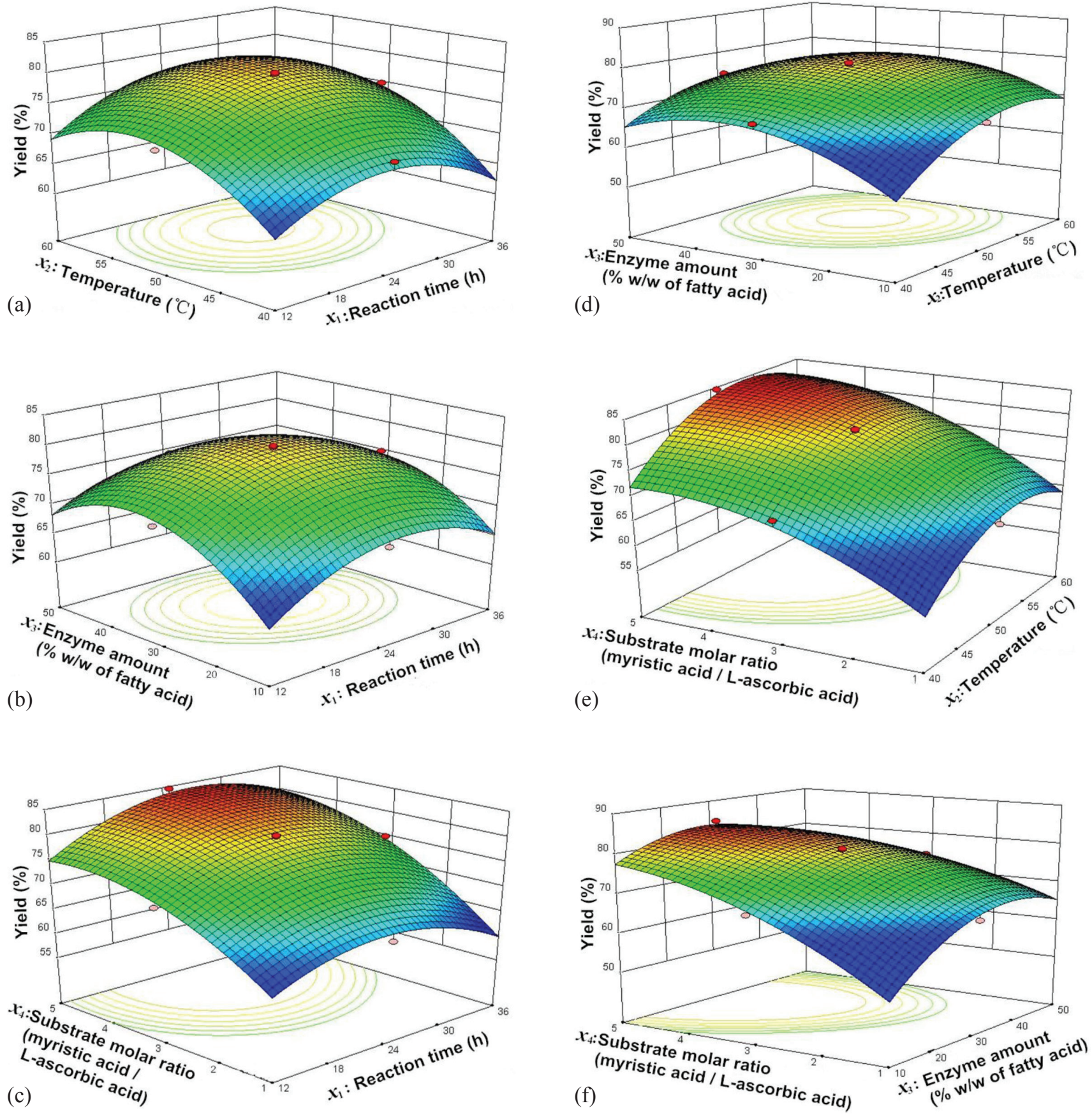

Fig. 1 - Response surface plot (3-D) showing the mutual effect of reaction time, temperature, enzyme amount, and molar ratio of myristic acid to ascorbic acid on the response (a) The molar ratio of myristic acid to ascorbic acid and the enzyme amount were fixed at 3 and $30 \%$, respectively (b) The molar ratio of myristic acid to ascorbic acid and the temperature were fixed at 3 and $50{ }^{\circ} \mathrm{C}$, respectively (c) The temperature and the enzyme amount were fixed at $50{ }^{\circ} \mathrm{C}$ and $30 \%$, respectively (d) The molar ratio of myristic acid to ascorbic acid and the reaction time were fixed at 3 and $24 \mathrm{~h}$, respectively (e) The reaction time and the enzyme amount were fixed at $24 \mathrm{~h}$ and $30 \%$, respectively (f) The temperature and the reaction time were fixed at $50{ }^{\circ} \mathrm{C}$ and $24 \mathrm{~h}$, respectively.

The effect of reaction time and different enzyme amount on esterification of L-ascorbyl myristate at constant temperature $\left(50{ }^{\circ} \mathrm{C}\right)$ and substrate molar ratio (3) is shown in Fig. 1b. The response surface plot presented a similar behavior as in Fig. $1 \mathrm{a}$. With the reaction time and enzyme amount increasing, the yield increased and then decreased when the time and enzyme amount were beyond 24 $\mathrm{h}$ and $30 \%$, respectively.
Fig. 1c presents the effect of varying reaction time and substrate molar ratio on the formation of L-ascorbyl myristate at $30 \%$ of enzyme amount and $50{ }^{\circ} \mathrm{C}$. At any given time from $12 \mathrm{~h}$ to $36 \mathrm{~h}$, an increase in substrate molar ratio led to higher yield, indicating that the substrate molar ratio is one of the most important factors affecting L-ascorbyl myristate formation. 
The effect of enzyme amount, temperature, and their reciprocal interaction on the synthesis of L-ascorbyl myristate at substrate molar ratio of 3 after $24 \mathrm{~h}$ is depicted in Fig. 1d. It was found that at any given enzyme amount from $10 \%$ to $50 \%$, an increase in temperature led to higher yield, indicating that the temperature also had significant effect on the biosynthesis of L-ascorbyl myristate.

Fig. 1e lists the effect of temperature and substrate molar ratio of myristic acid to ascorbic acid, and their reciprocal interaction on the synthesis of L-ascorbyl myristate. It was observed that the yield increased with substrate molar ratio increasing at any given temperature from $40{ }^{\circ} \mathrm{C}$ to $60{ }^{\circ} \mathrm{C}$, while the peak value of yield would appear at the temperature of $50{ }^{\circ} \mathrm{C}$. At the lowest temperature $(40$ ${ }^{\circ} \mathrm{C}$ ) with the lowest substrate molar ratio (1), the yield was only $56.6 \%$. The highest substrate molar ratio (5) at $50{ }^{\circ} \mathrm{C}$ could result in the yield reaching a maximum level of over $84.5 \%$. This indicated that the yield was greatly affected by temperature $\left(x_{2}\right)$ and substrate molar ratio $\left(x_{4}\right)$.

Fig. 1f presents the effect of varying enzyme amount and substrate molar ratio on the formation of L-ascorbyl myristate at $24 \mathrm{~h}$ and $50{ }^{\circ} \mathrm{C}$. It was found that with the substrate molar ratio increasing, the yield increased, while with the increase in enzyme amount, the yield firstly increased then de- creased above $30 \%$ of enzyme amount, which presented a similar behavior as in Fig. 1c and Fig. 1e.

\section{Obtaining optimum synthesis conditions}

The optimal conditions for the enzymatic synthesis of L-ascorbyl myristate was analyzed by using numerical optimization feature of Design Expert 8.0.5 software, which computes the estimated ridge of maximum response for increasing radii from the center of original design. The optimum reaction conditions with the maximum predicted yield was suggested as $85.2 \%$ at $27.1 \mathrm{~h}, 54.1{ }^{\circ} \mathrm{C}, 25.9 \%$ enzyme amount, and 5.0 of substrate molar ratio.

\section{Model verification}

The adequacy of the predicted model was examined by performing three additional independent experiments at the suggested optimum synthesis conditions. The average experimental yield was $85.0 \%$, which was consistent with the predicted value of $85.2 \%$. The good agreement between the experimental and predicted values indicated the validation of the RSM model.

\section{Structure identification of L-ascorbyl myristate}

The structure of the purified L-ascorbyl myristate which is white, was identified by ESI-MS and 1 HNMR. ESI-MS, as shown in Fig. 2, shows a

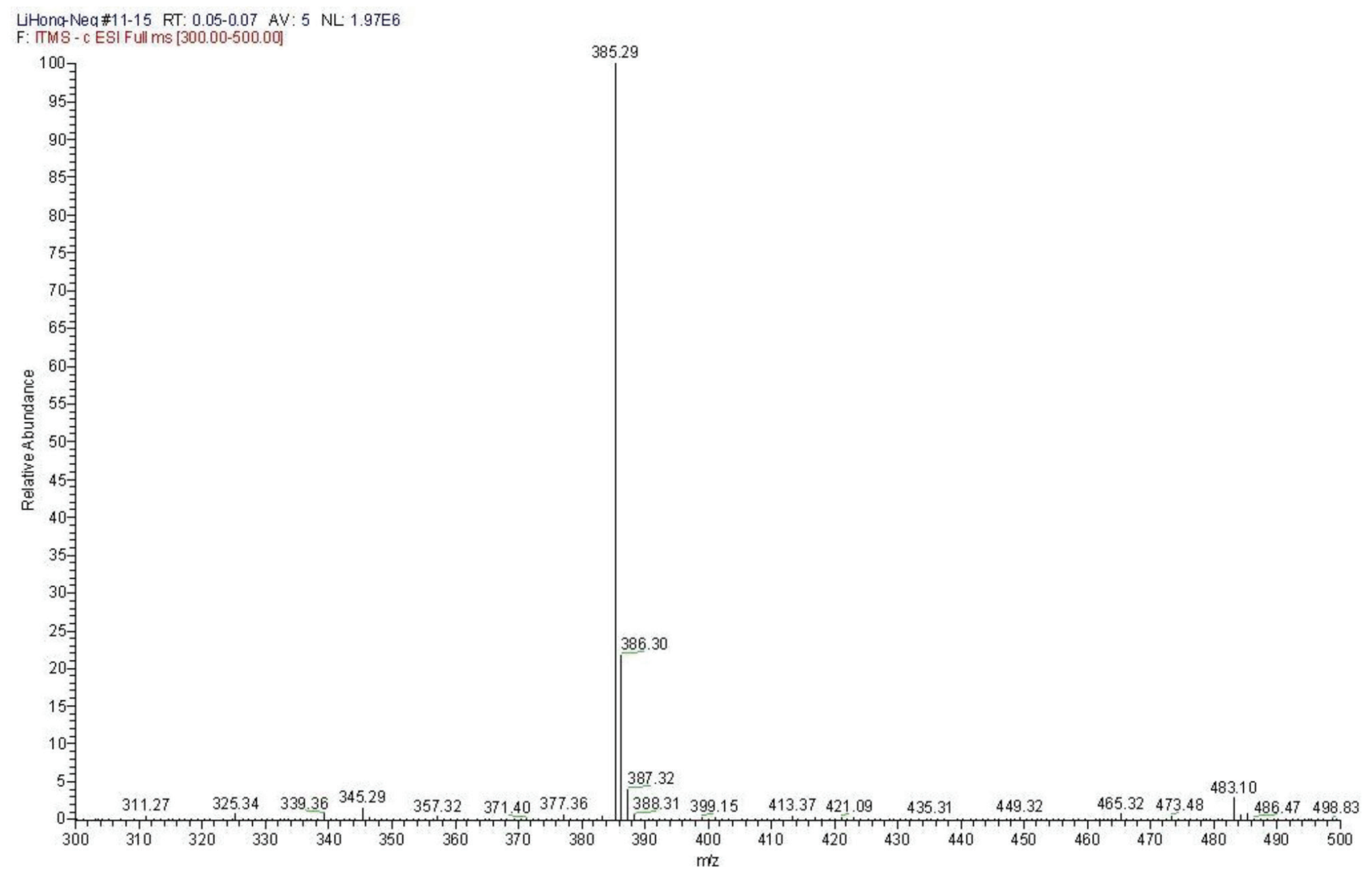

Fig. 2 - ESI-MS of L-ascorbyl myristate 


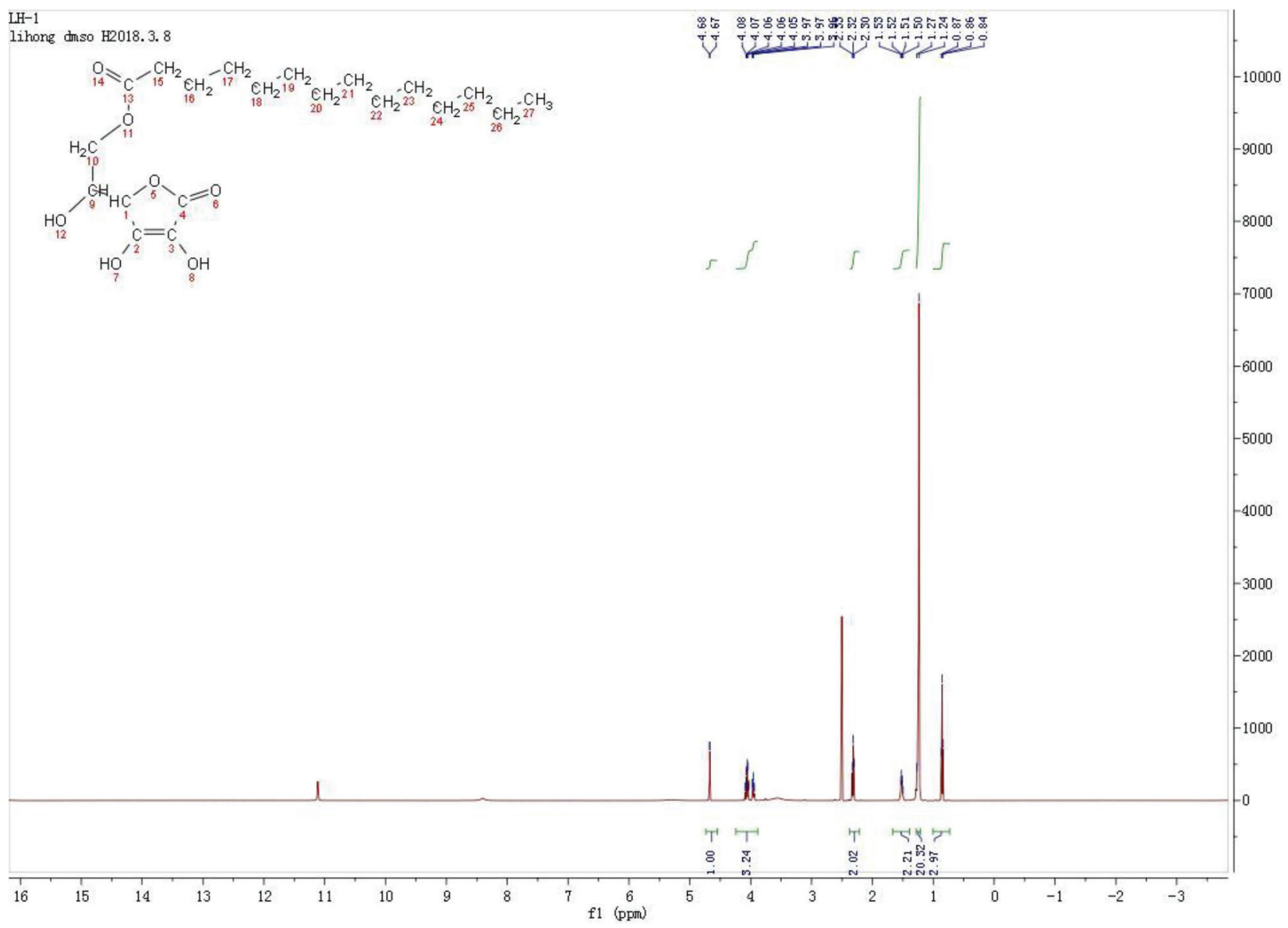

Fig. $3-1$ HNMR of L-ascorbyl myristate

main peak with $[\mathrm{M}-\mathrm{H}]$ molecular ions of 385.29 (MW 386.23), which can be characterized as L-ascorbyl myristate. The structure of L-ascorbyl myristate was verified by $1 \mathrm{H}$ NMR as shown in Fig. 3. The identification results wereas follows: $1 \mathrm{H}$ NMR (600 MHz, DMSO) $\delta 4.67(\mathrm{~d}, \mathrm{~J}=1.7 \mathrm{~Hz}$, $1 \mathrm{H}), 4.24-3.88(\mathrm{~m}, 3 \mathrm{H}), 2.32(\mathrm{t}, \mathrm{J}=7.4 \mathrm{~Hz}, 2 \mathrm{H})$, $1.52(\mathrm{dd}, \mathrm{J}=14.2,7.1 \mathrm{~Hz}, 2 \mathrm{H}), 1.25(\mathrm{~m}, 20 \mathrm{H}), 0.86$ $(\mathrm{t}, \mathrm{J}=7.0 \mathrm{~Hz}, 3 \mathrm{H})$, which are almost the same as the data reported in literature 22 . Both data indicated that the product was L-ascorbyl myristate.

\section{Conclusions}

The lipase-catalyzed synthesis of L-ascorbyl myristate by esterification of L-ascorbic acid and myristic acid in the presence of TBAB as ionic surfactant in 1,4-dioxane was investigated. Moreover, the optimum reaction conditions for maximal yield was studied by central composite design and response surface methodology. Based on the results of the four parameters evaluated, temperature, enzyme amount, and substrate molar ratio exhibited significant effect on the reaction. As the experiment was designed to utilize $25.9 \%$ enzyme amount and substrate molar ratio of 5 at $54.1{ }^{\circ} \mathrm{C}$ for $27.1 \mathrm{~h}$, an $85.0 \%$ maximum yield was obtained. Thus, the optimization of lipase catalyzed synthesis for L-ascorbyl myristate by Novozyme435 was successfully developed by CCD and RSM.

\section{ACKNOWLEDGEMENT}

This work was supported by the National Natural Science Foundation of China for Young Scholars (No. 31401661), Key Scientific and Technological Project of Henan Province (No. 172102110135), Key Scientific Research Projects in Colleges and Universities of Henan Province (No. 17A550007).

\section{References}

1. Villeneuve, P., Lipases in lipophilization reactions, Biotechnol. Adv. 25 (2007) 515. doi: https://doi.org/10.1016/j.biotechadv.2007.06.001

2. Karmee, S. K., Biocatalytic synthesis of ascorbyl esters and their biotechnological applications, Appl. Microbiol. Biotechnol. 81 (2009) 1013.

doi: https://doi.org/10.1007/s00253-008-1781-y

3. Karmee, S. K., The synthesis, properties, and applications of ascorbyl esters, Lipid Technology 23 (2011) 227. doi: https://doi.org/10.1002/lite.201100146 
4. Kaitaranta, J. K., Control of lipid oxidation in fish oil with various antioxidative compounds, J. Am. Oil Chem. Soc. 69 (1992) 810. doi: https://doi.org/10.1007/BF02635921

5. Naidu, K. A., Vitamin $\mathrm{C}$ in human health and disease is still a mystery? An overview, Nutrition J. 2 (2003) 7. doi: https://doi.org/10.1186/1475-2891-2-7

6. Han, D., Yi, O. S., Shin, H. K., Antioxidative effects of ascorbic acid solubilized in oils via reversed micelles, J. Food Sci. 55 (1990) 247. doi: https://doi.org/10.1111/j.1365-2621.1990.tb06062.x

7. Karmee, S. K., Lipase catalyzed synthesis of ester-based surfactants from biomass derivatives, Biofuels Bioprod. Bioref. 2 (2008) 144 doi: https://doi.org/10.1002/bbb.60

8. Liu, X. Y., Guo, F. L., Wu, L. M., Liu, Y. C., Liu, Z. L., Remarkable enhancement of antioxidant activity of vitamin $\mathrm{C}$ in an artificial bilayer by making it liposoluble, Chem. Phys. Lipids 83 (1996) 39. doi: https://doi.org/10.1016/0009-3084(96)02591-1

9. Sapers, G. M., El-Atawy, Y. S., Hicks, K. B., Garzarella, L., Effect of emulsifying agents on inhibition of enzymic browning in apple juice by ascorbyl palmitate, laurate, and decanoate, J. Food Sci. 54 (1989) 1096. doi: https://doi.org/10.1111/j.1365-2621.1989.tb07958.x

10. Perricone, N. V., Method for treating and preventing sunburn damage to the skin, US Patent. (1993) 5409693.

11. Jurkovic, P., Sentjurc, M., Gasperlin, M., Kristl, J., Pecar, $S$., Skin protection against ultraviolet induced free radicals with ascorbyl palmitate in microemulsions, Eur. J. Pharm. Biopharm. 56 (2003) 59 doi: https://doi.org/10.1016/S0939-6411(03)00062-6

12. Sonia, M. P., Marco, F., Jose, M. G., Gloria, F. L., Synthesis of ascorbyl oleate by transesterification of olive oil with ascorbic acid in polar organic media catalyzed by immobilized lipases, Chem. Phys. Lipids 174 (2013) 48. doi: https://doi.org/10.1016/j.chemphyslip.2013.06.003

13. Shlomo, Y., Sharon, R., Ralph, L. C., David, I. M., The role of polyunsaturated fatty acids in restoring the aging neuronal membrane, Neurobiol. Aging 23 (2002) 843. doi: https://doi.org/10.1016/S0197-4580(02)00074-X

14. Berg, J. J. M., Cook, N. E., Tribble, D. L., Reinvestigation of the antioxidant properties of conjugated linoleic acid, Lipids 30 (1995) 599. doi: https://doi.org/10.1007/BF02536996

15. Watanabe, Y., Sawahara, Y., Nosaka, H., Yamanaka, K., Adachi, S., Enzymatic synthesis of conjugated linoleoyl ascorbate in acetone, Biochem. Eng. J. 40 (2008) 368. doi: https://doi.org/10.1016/j.bej.2008.01.007

16. Cousins, K. C., Synthesis of 6-fatty acid ester of L-ascorbic acid, J. Am. Oil Chem. Soc. 54 (1997) 308. doi: https://doi.org/10.1007/BF02672431

17. Humeau, C., Girardin, M., Rovel, B., Miclo, A., Effect of thermodynamic water activity and the reaction medium hydrophobicity on the enzymatic synthesis of ascorbyl palmitate, J. Biotechnol. 63 (1998) 1. doi: https://doi.org/10.1016/S0168-1656(98)00069-8
18. Humeau, C., Girardin, M., Rovel, B., Miclo, A., Enzymatic synthesis of fatty acid ascorbyl esters, J. Mol. Catal. B: Enzymatic 5 (1998) 19. doi: https://doi.org/10.1016/S1381-1177(98)00090-3

19. Yan, Y. C., Bornscheuer, U. T., Schmid, R. D., Lipase-catalyzed synthesis of vitamin $\mathrm{C}$ fatty acid esters, Biotechnol. Lett. 21 (1999) 1051. doi: https://doi.org/10.1023/A:1005620125533

20. Zhang, D. H., Li, Y. Q., Li, C., Kinetics of enzymatic synthesis of L-ascorbyl acetate by lipozyme TLIM and Novozyme435, Biotechnol. Biopro. Eng. 17 (2012) 60. doi: https://doi.org/10.1007/s12257-011-0249-6

21. Lerin, L. A., Feiten, M. C., Richetti, A., Toniazzo, G., Treichel, H., Mazutti, M. A., Oliveira, J. V., Oestreicher, E. G., de Oliveira D., Enzymatic synthesis of ascorbyl palmitate in ultrasound-assisted system: Process optimization and kinetic evaluation, Ultrason. Sonochem. 18 (2011) 988. doi: https://doi.org/10.1016/j.ultsonch.2010.12.013

22. Kidwai, M., Mothsra, P., Gupta, N., Kumar, S. S., Gupta, $R$., Green enzymatic synthesis of L-ascorbyl fatty acid ester: An antioxidant, Synth. Commun. 39 (2009) 1143. doi: https://doi.org/10.1080/00397910802513045

23. Costa, I. C. R., Sutili, F. K., Silva, G. V. V., Leite, S. G. F., Miranda, L. S. M., Souza, R. O. M. A., Lipase catalyzed ascorbyl palmitate synthesis under microwave irradiation, J. Mol. Catal. B: Enzymatic. 102 (2014) 127. doi: https://doi.org/10.1016/j.molcatb.2014.02.002

24. Park, S., Viklund, F., Hult, K., Kazlauskas, R. J., Vacuum driven lipase-catalyzed direct condensation of L-ascorbic acid and fatty acids in ionic liquids: Synthesis of a natural surface active antioxidant, Green Chem. 5 (2003) 715. doi: https://doi.org/10.1039/b307715b

25. Adamczak, M., Bornscheuer, U. T., Improving ascorbyloleate synthesis catalyzed by Candida antarctica lipase B in ionic liquids and water activity control by salt hydrates, Process Biochem. 44 (2009) 257. doi: https://doi.org/10.1016/j.procbio.2008.10.014

26. Chen, B. L., Guo, Z., Let, M. B., Lue, B. M., Xu, X. B., Preparation of CLA ascorbyl ester with improved volumetric productivity by an ionic liquid-based reaction system, Org. Biomol. Chem. 6 (2008) 3196. doi: https://doi.org/10.1039/b807710j

27. Chang, S. W., Yang, C. J., Chen, F. Y., Akoh, C. C., Shieh, C. J., Optimized synthesis of lipase-catalyzed L-ascorbyl laurate by Novozyme435, J. Mol. Catal. B: Enzymatic 56 (2009) 7. doi: https://doi.org/10.1016/j.molcatb.2008.04.001

28. State Bureau of Technical Supervision of the People's Republic of China. Food additive - L-ascorbyl palmitate, National Standard of PRC.GB (1996) 16314.

29. Cochran, W. G., Cox, G. M., Experimental Designs. John Wiley \& Son Inc. New York. 1992.

30. SAS, SAS user guide, SAS Institute Inc., Cary, NC, 1990.

31. Avramović, J. M., Stamenković, O. S., Todorović, Z. B., Lazić, M. L., Veljković, V. B., The optimization of the ultrasound-assisted base-catalyzed sunflower oil methanolysis by a full factorial design, Fuel Process Technol. 91 (2010) 155. doi: https://doi.org/10.1016/j.fuproc.2010.06.001 